Meta

Journal des tradlucteurs

Translators' Journal

\title{
BALLARD, Michel (1992) : Le commentaire de traduction anglaise, Paris, Nathan, 128 p.
}

\section{Anne-Marie Loffler-Laurian}

Volume 38, numéro 4, décembre 1993

Le $J e$ du traducteur

The $I$ of the Translator

URI : https://id.erudit.org/iderudit/003421ar

DOI : https://doi.org/10.7202/003421ar

Aller au sommaire du numéro

Éditeur(s)

Les Presses de l'Université de Montréal

ISSN

0026-0452 (imprimé)

Découvrir la revue

Citer ce compte rendu

Loffler-Laurian, A.-M. (1993). Compte rendu de [BALLARD, Michel (1992) : Le commentaire de traduction anglaise, Paris, Nathan, 128 p.] Meta, 38(4), 724-725. https://doi.org/10.7202/003421ar d'utilisation que vous pouvez consulter en ligne.

https://apropos.erudit.org/fr/usagers/politique-dutilisation/ 
BALLARD, Michel (1992): Le commentaire de traduction anglaise, Paris, Nathan, $128 \mathrm{p}$.

Le commentaire de traduction anglaise de Michel Ballard est un petit ouvrage qui s'adresse aux étudiants et propose de les «aider à comprendre, aider à agir, aider à 
réfléchir». On voit donc qu'il ne s'agit pas de donner des recettes de traduction, ni même des conseils à proprement parler. Il s'agit ici de proposer une réflexion sur la nature de l'opération qui nous permet de passer d'une langue à l'autre.

Dans un chapitre consacré aux principes méthodologiques, l'auteur définit et décrit la notion d'unité de la traduction à travers les divers types d'équivalences. Il analyse aussi d'autres aspects de cette unité : son oralité, son idiomaticité, et son aspect phrastique, domaine qu'il développe particulièrement.

Dans une deuxième partie, il propose divers commentaires de traduction classés en commentaires autocorrectifs et commentaires comparés. Onze commentaires sont ainsi développés.

L'ouvrage s'achève sur des propositions de recherche sur corpus selon huit thèmes: type d'équivalence, titre, collocation, relation hypero-hyponymique, dépronominalisation, différence de concentration, be + prédicat, and.

Extrêmement clair et structuré, ce petit volume est, en outre, très agréable à lire, grâce au style parfaitement précis de Michel Ballard. Il est inutile de connaitre les dernières théories à la mode ou la dernière phraséologie linguistique de mise, pour comprendre ce livre. C'est là l'un de ses atouts majeurs: son accessibilité, sa simplicité, sa clarté. On ne saurait trop le recommander aux étudiants comme aux enseignants.

ANNE-MARIE LOFFLER-LAURIAN Université de la Sorbonne Nouvelle-Paris III, Paris, France 